\title{
Memory Complaint in a Community Sample Aged 70 and Older
}

\author{
Carolyn L. Turvey, PhD, ${ }^{+\dagger}$ Susan Schultz, MD, ${ }^{\dagger \neq}$ Stephan Arndt, PhD, ${ }^{* \dagger}$ Robert B. Wallace, MD, \\ and Regula Herzog, $P h D^{\S}$
}

OBJECTIVES: The ability of older people to estimate their own memory, often referred to as "metamemory," has been evaluated in previous studies with conflicting reports regarding accuracy. Some studies have suggested that an older person's metamemory is mostly accurate, whereas others have demonstrated little relationship between memory complaint and actual impairment. This study examines memory complaint in a large national sample of older people aged $\geq 70$.

DESIGN: A longitudinal cohort study with two waves of data collection spaced 2 years apart.

SETTING: A nationwide random sample of communitydwelling older persons.

PARTICIPANTS: A total of 5444 community-dwelling persons aged $\geq 70$ and their spouses.

MEASUREMENTS: Participants were asked if they believed their memory was excellent, very good, good, fair, or poor. They were then administered a cognitive assessment derived from the Mini-Mental Status Exam.

RESULTS: In general, people's assessment of their memory corresponded with their actual performance on cognitive measures. However, large portions of the sample inaccurately assessed their memory skills. People who reported depressive symptoms and had impairment in activities of daily living were more likely to state that their memory was impaired, although they performed very well on cognitive measures.

CONCLUSIONS: The conditions that skew people's selfassessment are the ones most likely to bring them into contact with healthcare professionals. This may give clinicians the general impression that older people cannot assess their own cognitive skills. However, poor metamemory appears to be a

From the "Department of Preventive Medicine and Environmental Health, The University of Iowa; tDepartment of Psychiatry, College of Medicine, The University of Iowa; $¥$ Mental Health Clinical Research Center, Department of Psychiatry, University of Iowa, Iowa City, Iowa; and SInstitute for Social Research, Institute of Gerontology, Department of Psychology, The University of Michigan, Ann Arbor, Michigan.

This research was supported, in part, by the National Institute of Health Training Grant for Mental Health Epidemiology and Biometry 2T3ZMH1568-20 to Dr. Turvey; National Institute of Health Grant 1 U01 AG12980 as part of the project entitled "The Oldest Old Supplement to the Health and Retirement Survey"; National Institute of Health Grant 1-21152 00 "Health and Retirement Study" to Drs. Wallace and Herzog; and National Institute of Mental Health Grants P50 MH43271, MH40856, and MH31593 to Dr. Arndt.

Address correspondence and reprint requests to Carolyn Turvey, PhD, Psychiatry Research-MEB, University of lowa, lowa City, IA 52242-1000. characteristic of a specific subgroup of older persons, not necessarily characteristic of the general population. J Am Geriatr Soc 48:1435-1441, 2000.

Key words: memory; metamemory; depression; older people

$\mathrm{O}$ Ider individuals must be able to assess their memory skills to function safely in their everyday lives. For example, older people who are unaware of memory deficits may continue to engage in potentially dangerous tasks such as cooking, automobile driving, or traveling. Conversely, those with good memory but who believe they are impaired may seek unnecessary evaluations or treatment and limit their activities needlessly. The ability to estimate one's own memory, often referred to as "metamemory," has been evaluated in previous studies with conflicting reports regarding accuracy. Although some studies ${ }^{1-5}$ have suggested that metamemory is mostly accurate, other studies ${ }^{6-10}$ have demonstrated little relationship between memory complaints and actual impairment. Several reasons may account for these conflicting findings, including different study populations, different definitions of accuracy, and the possibility of subgroups with different levels of concordance. It seems that the question is not so much whether people can assess their memory, but which characteristics define those individuals with poor metamemory. This study examines memory complaint in a large national sample of older people aged $\geq 70$.

The initial objective of this study involved defining "inaccuracy." There are two general ways that people can inaccurately assess their memory. First, there are those people whose memory is poor, yet they do not acknowledge it. Second, there are those who have good memory, yet they report impairment. The former group may not acknowledge impairment because the factors that lead to memory impairment may also compromise one's ability to assess memory, i.e., intact memory and other cognitive processes that may be needed to accurately assess memory. ${ }^{11}$ On the other hand, individuals may be aware of their deficits, yet they are hesitant to report them because they assume reasonably that others may impose restrictions on their independent functioning. Moreover, the accurate assessment of memory may be a difficult and complex task, whether one is impaired or not. ${ }^{12,13}$

Most research on metamemory asks subjects a general question such as, "How would you rate your memoryexcellent, good, fair, or poor?" Unfortunately, this question 
can be understood in one of two ways. A subject may believe either that he or she is being asked about memory skills relative to others or he or she is being asked about current memory skills as compared with his or her skills in the past. Although both are relevant to functioning, geriatricians are most concerned with the latter question because change reflects a pathological process that will likely lead to further decline. Therefore, it is important to obtain specific assessment of the subject's perception of memory.

There are several ways to conceptualize why some people report memory difficulties in the absence of any true impairment. It is possible that they may be sensitive to subtle memory problems that are not assessed well by standard memory tests. Schmand et al. ${ }^{14}$ found that subjective memory complaints predict future cognitive decline, suggesting that a subgroup of older persons may be sensitive to prodromal manifestations of memory decline that are not reflected in current cognitive tests. Others ${ }^{15}$ have failed to find such an association. It is also possible that memory complaints are rooted in another unrelated disturbance. For example, people with health concerns or psychiatric disturbance often report cognitive decline. Depression has received the most attention because it has been shown that people with intact memory who report impairment have higher rates of depression. ${ }^{16-19}$ It is unclear whether the memory complaint results from the general negativity of depression or whether a pathophysiological process unique to depression impairs the individual's ability to self-assess his or her memory function.

This study used a large community-based sample to examine memory complaint. We first examined the concordance between people's assessment of their own memory and their performance on tests of memory, comprehension, and orientation. For further analysis, a subject's change in cognitive performance after a 2-year interval was used to form two groups, those with the greatest improvement in performance and those with the most cognitive decline. Within these two groups, those who reported a decline in memory and those who reported no change or improvement in memory were compared with respect to demographic and clinical variables. This design allowed us to examine memory complaint in those whose memory had deteriorated and in those whose memory abilities remained stable. Using these two groups, we addressed the following questions: (1) Which demographic and clinical variables characterize individuals who do not acknowledge memory decline when their performance had actually declined? (2) Which demographic and clinical variables characterize individuals whose performance on cognitive measures have improved, but who reported memory decline? (3) Are people who report poor memory when they perform above average on cognitive measures more likely to show later cognitive decline, suggesting that they were sensitive to subtle prodromal impairment?

\section{METHODS}

\section{Sample}

AHEAD (Asset and Health Dynamics Among the Oldest $\left.\mathrm{Old}^{20}\right)$ is a companion study to the Health and Retirement Survey ${ }^{21}$ and is intended to investigate the impact of changes in health status on financial management and service and public program utilization, and intergenerational transfer of assets in older people. AHEAD participants were a nationally representative, multistage probability sample of individuals.
The two sampling frames for the study were the 1991 screening of housing units enumerated for the Health and Retirement Survey and the Health Care Finance Administration's Master Enrollment file of Medicare enrollees who were living in a household. Primary respondents had to be $\geq 70$ years old and, if married, their partners participated regardless of their partner's age. Although the initial sampling frame excluded institutionalized older persons, the respondents who were institutionalized after an initial assessment (Wave 1) remained in the sample and were interviewed at Wave 2, a longitudinal follow-up assessment occurring 2 years later.

The first wave of AHEAD occurred in 1993-94, the second wave in 1995-96. Wave 1 included 8406 respondents. Of these, 828 died between Wave1 and Wave 2, for whom 775 family members or close acquaintances completed proxy interviews describing the circumstances of their spouse's death. Of the 7578 living at Wave 2, 7038 completed the second interview, yielding a $93 \%$ follow-up rate. Depression and cognitive measures were not administered to the respondents receiving proxy interviews at either Wave1 or Wave $2(n=901)$. Proxy interviews were administered when the respondent declined an interview for any reason and a close acquaintance was willing or available. People who had poor cognitive status were not systematically selected for proxy interviews, although it is possible that the more impaired respondents would be more likely to refuse further participation in interviews. Because this study was interested in memory complaint in people aged $\geq 70$, spouses younger than $70(n=678)$ were excluded. In addition, 15 subjects did not provide information on the key variables of interest, thereby limiting the sample size for analyses to 5444 . Sample sizes for specific analyses varied as a result of missing data on key variables for some respondents. The AHEAD 2 data set is a preliminary data set intended for public release in 2000.

Whereas people aged 70 to 79 were interviewed by telephone, those persons aged $\geq 80$ were interviewed in person. All participants provided verbal informed consent and internal ethics review board approval was obtained. Interviewers underwent a 1-week training session conducted at the University of Michigan Survey Research Center. Interviewers conducted several trial interviews and received extensive feedback before they were authorized to conduct interviews in the field. All interviews collected in the field were reviewed by an interview supervisor.

\section{Cognitive Measures}

Cognitive measures were administered in all nonproxy interviews at both Wave 1 and Wave 2 . The measures were the same in both waves, allowing for longitudinal analysis. There was a slight alteration in content, specifically for measures of recall, to minimize learning effects.

At both Wave 1 and Wave 2, the respondents were asked before the administration of the cognitive measures, "How would you rate your memory at the present time? Would you say it was excellent, very good, good, fair, or poor?" At the Wave 2 interview, the respondents were asked the same question and they were also asked, "Compared with (date of Wave 1 interview), 2 years ago, would you say your memory is better now, about the same, or worse now than it was then?" The participants were then administered the cognitive measures. 
The development of the AHEAD cognitive measures were derived from the psychological research on intelligence and cognition as well as geriatric and neurological research on dementia. ${ }^{22}$ Many of the measures were adapted from the Telephone Interview for Cognitive Status (TICS), ${ }^{23}$ which was modeled after the Mini-Mental State $\mathrm{Exam}^{24}$ to be administered over the telephone. The original TICS correlated highly (Pearson $r=.94$ ) with a Mini-Mental Status Exam administered directly, and the TICS had a sensitivity of $94 \%$ and a specificity of $100 \%$ in discriminating between 16 patients with Alzheimer's disease and 33 normal control patients. ${ }^{23}$ The full cognitive assessment included:

1. The Serial 7s test of working memory. One point was given for each correct subtraction from 100 in increments of 7 for a maximum of 5 points.

2. Immediate and delayed free-recall. Ten short, concrete high-frequency nouns were read to the respondent who was asked to recall as many as possible immediately and then again after approximately a 5-minute delay. In this study, immediate and delayed recall were examined separately with scores on both measures ranging from 0 items remembered to all 10 items remembered.

3. A modified mental status exam where respondents were asked to name the day of the week, date, including the month, day, and year; name the president and vice-president; and name the objects that "people usually cut paper with" and the "kind of prickly plant that grows in the desert." Respondents were also asked to count backward from 20 to 10. The range for the mental status measure was from 0 to 10 .

The cognitive measures were examined separately and then a total score was used by summing the serial 7 , recall, and mental status scale totals. Using the total cognitive score as a summary, the measure was validated in a prior study that found the clinical and demographic correlates of the total score to be comparable with those of the individual scales. ${ }^{22}$ Cognitive decline was calculated by subtracting the Wave 1 total cognitive score from the Wave 2 total cognitive score.

\section{Psychiatric Measures}

History of a major depressive syndrome was determined using a short form of the Composite International Diagnostic Interview (short-form CIDI), a structured interview originally developed by the World Health Organization, ${ }^{25}$ which was subsequently adapted for the National Comorbidity Study. ${ }^{26}$ The short-form CIDI consists of the symptoms that best predicted caseness on the full UM-CIDI using logistic regression ( $R$. Kessler, D. Mroczek, Information on the development of mental health screening scales for the US National Health Interview Survey, unpublished data). It assesses eight of the nine possible associated symptoms required for the diagnosis of a depressive episode by DSM-IV criteria. ${ }^{27}$ The major difference between this measure and the full CIDI is that motor slowing was not assessed and the exclusionary criteria for medical illness and bereavement were not applied. The threshold of five or more symptoms, one of which must be depressed mood or anhedonia and a 2-week duration was required for diagnosis. A 1-year prevalence, not lifetime prevalence, was assessed.

A revised 8-item version of the Center for Epidemiologic Studies-Depression Scale (CES-D) was also administered. ${ }^{28} \mathrm{~A}$ prior analysis of the AHEAD data showed that the revised CES-D had adequate internal reliability (Cronbach's alpha = $r=.78)$ and a comparable factor structure and distribution to the larger full-item scale. ${ }^{29}$ The revised CES-D contained a simple yes/no format for each question. Each subject was asked to endorse the item if he or she experienced the symptom "much of the time during the past week."

\section{Health Measures}

At both Wave 1 and Wave 2, the participants reported whether they had been previously diagnosed with cancer, diabetes, high blood pressure, lung disease, heart problems, stroke, and/or arthritis by a physician or other healthcare provider. In the service of brevity, health status was quantified as the total number of medical illnesses endorsed by the subjects.

\section{Functional Status}

Measures of the respondent's functioning on activities of daily living (ADLs) and instrumental activities of daily living (IADLs) were assessed. In the ADL assessment, the respondents reported whether they needed help walking, dressing, bathing, eating, getting into bed, and using the bathroom. ${ }^{30}$ These items were selected based on the original instrument described by Katz et al., ${ }^{31}$ and subsequent revisions by Kane and $\mathrm{Kane}^{32}$ and Weiner et al. ${ }^{33}$ The assessment of IADLs included meal preparation, grocery shopping, telephone use, taking medication, and managing money. Item selection was based on Fillenbaum's ${ }^{34}$ revision of Lawton and Brody's ${ }^{35}$ original measure of IADLs.

In this study, the respondents were coded categorically as having any versus no difficulty in ADLs and IADLs. A dichotomous model was selected over a scale based on the number of ADLs or a composite of both the number and degree of difficulty in ADLs. Prior analyses, using such continuous models, yielded results which were similar to those reported in this article based on the dichotomous scale but they were less interpretable because $75 \%$ of the sample reported no difficulty in ADLs and $66 \%$ reported no difficulty in IADLs. The mean number of ADLs for the entire sample was 0.52 and the mean for IADLs was 0.59 ; the comparisons based on the means were difficult to conceptualize for clinical practice. Therefore, the results were presented using a dichotomous model of impairment in ADLs and IADLs.

\section{Statistical Analysis}

Analysis of variance was used to compare continuous scores on each of five cognitive measures between the five categorical groups based on the subjects' reports of their memory abilities. Comparisons between subjects who reported memory decline and those who reported stable or improved memory were made using $t$ test for continuous variables and chi-square tests for categorical variables. The analysis of whether memory complaint at Wave 1 predicted decline by Wave 2 used a $t$ test to compare a continuous measure of decline between the two groups. In addition, a general linear model compared decline between the two groups although controlling for actual cognitive score at Wave 1. To control for multiple comparisons and large sample size, a significance level was set at $P<.001$. All tests were two-tailed.

\section{RESULTS}

\section{Can People Assess Their Own Memory?}

The means and standard deviations for the entire Wave 2 sample on cognitive measures are presented in Table 1 . The 
Table 1. Scores on Memory and Mental Status Tests for Each Group of Self-Rating of Memory

\begin{tabular}{|c|c|c|c|c|c|c|}
\hline $\begin{array}{l}\text { Self-Rating of } \\
\text { Memory }\end{array}$ & $N(\%)$ & Serial $7^{*}$ & $\begin{array}{l}\text { Immediate } \\
\text { Recall }^{\dagger}\end{array}$ & $\begin{array}{l}\text { Delayed } \\
\text { Recall }{ }^{\ddagger}\end{array}$ & $\begin{array}{l}\text { Mental } \\
\text { Status }\end{array}$ & $\begin{array}{l}\text { Total } \\
\text { Cognitive } \\
\text { Score }\end{array}$ \\
\hline $\begin{array}{l}\text { Range } \\
\text { Total sample } \\
\text { Excellent }\end{array}$ & $\begin{array}{l}5444 \\
419 \text { (7.7\%) }\end{array}$ & $\begin{array}{c}0-5 \\
3.0 \pm 1.9 \\
3.2 \pm 1.8\end{array}$ & $\begin{array}{c}0-10 \\
4.6 \pm 1.9 \\
4.9 \pm 1.9\end{array}$ & $\begin{array}{c}0-10 \\
3.2 \pm 2.2 \\
3.6 \pm 2.3\end{array}$ & $\begin{array}{c}0-10 \\
8.9 \pm 1.6 \\
9.1 \pm 1.4\end{array}$ & $\begin{array}{c}0-35 \\
19.7 \pm 5.9 \\
20.9 \pm 5.8\end{array}$ \\
\hline Very good & $1203(22.1 \%)$ & $3.3 \pm 1.8$ & $4.9 \pm 1.9$ & $3.6 \pm 2.2$ & $9.1 \pm 1.4$ & $20.9 \pm 5.6$ \\
\hline Good & $2211(40.6 \%)$ & $3.1 \pm 1.8$ & $4.7 \pm 1.8$ & $3.3 \pm 2.2$ & $9.0 \pm 1.4$ & $20.2 \pm 5.6$ \\
\hline Fair & $1276(23.4 \%)$ & $2.7 \pm 1.9$ & $4.2 \pm 1.8$ & $2.8 \pm 2.0$ & $8.7 \pm 1.6$ & $18.5 \pm 5.6$ \\
\hline Poor & $335(6.1 \%)$ & $1.9 \pm 1.9$ & $3.4 \pm 1.8$ & $2.0 \pm 1.9$ & $7.7 \pm 2.2$ & $15.0 \pm 6.2$ \\
\hline
\end{tabular}

${ }^{\natural} \mathrm{F}(4,5439)=51.0, P<.001 ;{ }^{\dagger} \mathrm{F}(4,5439)=61.7, P<.001{ }^{\ddagger} \mathrm{F}(4,5439)=54.4, P<.001 ;{ }^{5} \mathrm{~F}(4,5439)=65.9, P<.001 ;{ }^{\mathrm{T}} \mathrm{F}(4,5439)=94.9, P<.001$.

Note: Groups based on self-rating of memory were compared on each of five cognitive measures using analysis of variance.

total sample is categorized according to how the participants rated their memory. There was an association between selfrating of memory and actual scores for each measure and for the total cognitive score. The respondents who rated their memory as "fair" or "poor" had lower scores than those who rated their memory as "good," "very good," or "excellent." The total sample mean always fell between the mean for those rating their memory as "good" and those rating their memory as "fair." However, those who rated their memory as "excellent" did not necessarily perform better than those who rated their memory as "very good" or "good."

The participants' memory assessment corresponded to their cognitive performance overall. However, for those who inaccurately assessed their memory, they tended to underestimate their impairment. Table 2 includes the total cognitive score grouped into quartiles adjacent to the percentage of respondents in each of those quartiles who reported "good," "very good," or "excellent" memory. Once again, there was a clear association between self-rating of memory and actual performance. The percentage of respondents who reported "good," "very good," or "excellent" memory decreased as the percentile ranking decreased. However, it should be noted that $57 \%$ of the subjects in the lowest quartile stated that their memory was "good," "very good," or "excellent."

Table 2. Percent of Respondents Who Report Good, Very Good, or Excellent Memory in Each of Four Cognitive Performance Levels Based on Total Cognitive Score

\begin{tabular}{|c|c|c|c|}
\hline $\begin{array}{c}\text { Cognitive } \\
\text { Performance Based } \\
\text { on Total } \\
\text { Score-Quartiles }\end{array}$ & $n=5444$ & $\begin{array}{c}\text { Total } \\
\text { Cognitive } \\
\text { Score } \\
\text { (mean } \pm \text { SD) }\end{array}$ & $\begin{array}{c}\% \text { Reporting } \\
\text { Good, Very } \\
\text { Good, or } \\
\text { Excellent } \\
\text { Memory }\end{array}$ \\
\hline Highest & 1141 & $27 \pm 2.1$ & 82 \\
\hline High average & 1546 & $22 \pm 1.1$ & 76 \\
\hline Low average & 1298 & $19 \pm 1.1$ & 69 \\
\hline Lowest & 1459 & $12 \pm 3.5$ & 57 \\
\hline
\end{tabular}

A similar analysis was conducted using the subjects' responses to the question about cognitive decline. The question about cognitive decline was less ambiguous because it specifically asks the subject to compare their current memory with their memory in the past. The subjects tended to minimize impairment even when they categorized the sample using the quartiles based on decline in cognitive score since Wave 1 (Table 3). Of those who showed the most cognitive decline, $76 \%$ reported stable or improved memory when compared with Wave 1.

\section{What Characteristics Define Those with Poor Metamemory?}

The two types of inaccuracy discussed in the introduction were examined: (1) failure to perceive memory decline when it has occurred, and (2) perceived impairment in the presence of intact cognition.

A measure of cognitive change was derived by subtracting Wave 1 total cognitive score from Wave 2 total cognitive score. On average, the sample showed a slight decline on their total cognitive score, with a mean change between Wave 1 and Wave 2 of -0.34 ( $S D=4.3$; range, -21 to +18 ). The respondents who scored within the lowest 10th percentile on

Table 3. Percent of Respondents Who Report Stable or Improved Memory in Each of Four Cognitive Performance Levels Based on Change in Total Cognitive Score since Wave 1

\begin{tabular}{|c|c|c|c|}
\hline $\begin{array}{c}\text { Cognitive Decline } \\
\text { Based on Change } \\
\text { in Total } \\
\text { Score-Quartiles }\end{array}$ & $n=5122^{*}$ & $\begin{array}{l}\text { Total Change } \\
\text { Since Wave } 1 \\
\text { (mean } \pm \text { SD) }\end{array}$ & $\begin{array}{l}\text { \% Reporting } \\
\text { Memory Is } \\
\text { Stable or } \\
\text { Improved } \\
\text { Since Wave } 1\end{array}$ \\
\hline $\begin{array}{l}\text { Most improvement } \\
\text { Mild improvement } \\
\text { Mild decline } \\
\text { Most decline }\end{array}$ & $\begin{array}{r}1217 \\
972 \\
1474 \\
1459\end{array}$ & $\begin{array}{l}+5 \pm 2.3 \\
+1 \pm 0.5 \\
-1.0 \pm 0.8 \\
-5 \pm 2.7\end{array}$ & $\begin{array}{l}83 \\
81 \\
78 \\
76\end{array}$ \\
\hline
\end{tabular}


this change score (a decrease of $\geq 6$ points on the total cognitive measure) were divided into two groups: (1) those who endorsed "the same" or "better" memory, and (2) those who endorsed that their memory was "worse". A decline of $\geq 6$ points is equal to about $1.5 \mathrm{SD}$ below the mean for the entire sample. Because this subgroup was selected based on a substantial decline in their cognitive scores, those who said their memory was "good" or "better" did not acknowledge their cognitive decline and were, therefore, less accurate.

Gender $\left(\chi^{2}=0.38, d f=1, P=.54\right)$, marital status $\left(\chi^{2}=\right.$ 4.1, $d f=2, P=.13)$, education $\left(\chi^{2}=1.3, d f=1, P<.26\right)$, and presence of a chronic medical illness $\left(\chi^{2}=3.4, d f=1\right.$, $P=.06)$ did not differ between the two groups (Table 4). Age (t-equal variance $(d f=547)=-2.47, P<.02)$ did not reach the $a$ priori threshold for significance, suggesting the possibility of an association between age and memory complaint, albeit a weak one. In contrast, people whose functioning on ADLs $\left(\chi^{2}=28.2, d f=1, P<.001\right)$ and IADLs $\left(\chi^{2}=18.7\right.$, $d f=1, P<.001$ ) was still intact did not acknowledge their memory decline. In addition, those who did not acknowledge memory decline had fewer depressive symptoms ( $t$-unequal variance $(d f=230)=-4.18, P<.001)$ than those who did. Differences between the rates of syndromal depression $\left(\chi^{2}=\right.$ 4.6, $d f=1, P<.03$ ) did not reach the threshold for significance.

A similar pattern was found for those who reported impairment although they improved the most on the total cognitive score since Wave 1 (Table 5). On average, this

Table 4. Differences Between Subjects Who Do and Who Do Not Acknowledge Memory Decline in the Subsample With the Greatest Cognitive Decline Between Wave 1 and Wave 2

\begin{tabular}{lcc}
\hline & \multicolumn{2}{c}{$\begin{array}{c}\text { Most Cognitive Decline } \\
\text { Self-Rating of Cognitive Decline }\end{array}$} \\
\cline { 2 - 3 } & $\begin{array}{c}\text { Memory Stable } \\
\text { or Improved }\end{array}$ & Memory Decline \\
\hline $\mathrm{n}$ & 398 & 151 \\
Demographics & & \\
Age in years & $80(5)$ & $81(5)^{\star}$ \\
\% Male & 35 & 38 \\
Marital status (\%) & & 5 \\
Single & 11 & 42 \\
Married & 41 & 52 \\
Widowed & 48 & 66 \\
\% with high school & 60 & \\
$\quad$ degree & & $2.4(2.4)^{\ddagger}$ \\
Depression & & $5^{\star}$ \\
8-item CES-D & $1.5(1.9)$ & \\
Depression (\%) & 2 & $49^{\ddagger}$ \\
Functioning & & $56^{\ddagger}$ \\
\% w/any ADLs & 25 & \\
\% w/any IADLs & 35 & \\
\% w/any medical & 77 & \\
illnesses & &
\end{tabular}

${ }^{*} P<.05 ;{ }^{\ddagger} P<.001$. Only comparisons that reach the $P<.001$ level of significance or lower are considered significant.

Note: Sample selected by taking subjects whose Wave 2 cognitive score minus Wave 1 cognitive score fell in the lowest 10th percentile.

CES-D, Center for Epidemiologic Studies; Depression Scale; ADLs, activities of daily living; IADLs, instrumental activities of daily living.
Table 5. Differences Between Respondents Who Do and Who Do Not Report Memory Improvement in the Subsample With the Greatest Cognitive Improvement Between Wave 1 and Wave 2

\begin{tabular}{|c|c|c|}
\hline & \multicolumn{2}{|c|}{$\begin{array}{l}\text { Respondents Whose Memory } \\
\text { Improved the Most } \\
\text { Self-Rating of Cognitive Decline }\end{array}$} \\
\hline & $\begin{array}{l}\text { Memory Stable } \\
\text { or Improved }\end{array}$ & Memory Decline \\
\hline$n$ & 495 & 98 \\
\hline \multicolumn{3}{|l|}{ Demographics } \\
\hline Age in years & $79(5)$ & $80(5)^{*}$ \\
\hline$\%$ Male & 37 & 32 \\
\hline \multicolumn{3}{|l|}{ Marital status (\%) } \\
\hline Single & 8 & 12 \\
\hline Married & 46 & 49 \\
\hline Widowed & 46 & 39 \\
\hline $\begin{array}{l}\% \text { with high school } \\
\text { degree }\end{array}$ & 60 & 61 \\
\hline \multicolumn{3}{|l|}{ Depression } \\
\hline 8-item CES-D & $1.3(1.7)$ & $2.3(2.2)^{\ddagger}$ \\
\hline CIDI Dep. (\%) & 1.8 & $6.1^{\star}$ \\
\hline \multicolumn{3}{|l|}{ Functioning } \\
\hline$\%$ w/any ADLs & 17 & $42^{\ddagger}$ \\
\hline$\%$ w/any IADLs & 29 & 38 \\
\hline $\begin{array}{l}\% \text { w/any medical } \\
\text { illnesses }\end{array}$ & 77 & $88^{*}$ \\
\hline
\end{tabular}

${ }^{*} P<.05 ;{ }^{\ddagger} P<.001$. Only comparisons that reach the $P<.001$ level of significance or lower are considered significant.

Note: Sample selected by taking subjects whose Wave 2 cognitive score minus the Wave 1 cognitive score on the total measure was actually positive and in the top 10 th percentile for the entire sample.

CES-D, Center for Epidemiologic Studies-Depression Scale; CIDI, Composite International Diagnostic Interview; ADLs, activities of daily living; IADLs, instrumental activities of daily living.

group's total cognitive score improved 7 points between Wave 1 and Wave 2. This is equal to an improvement of about $1.5 \mathrm{SD}^{\mathrm{B}}$ above the mean for the total sample. Nonetheless, $17 \%$ reported that their memory declined between interviews. Once again, demographic variables did not differ between groups, but depressive symptoms ( $t$-unequal variance $(d f=122)=-4.4, P<.001)$, more so than syndromal depression $\left(\chi^{2}=6.1, d f=1, P<.01\right)$, was a strong predictor of memory complaint. Functioning on ADLs $\left(\chi^{2}=29.7, d f=\right.$ $1, P<.001)$, but not IADLs $\left(\chi^{2}=3.0, d f=1, P<.08\right)$ was strongly associated with memory complaint.

\section{Does Perceived Impairment Predict Future Deterioration?}

For this analysis, we wanted to test whether those who do not show any indication of impairment but do report poor memory are more likely to show decline. Therefore, we needed to limit the sample to those with no evident impairment on the total cognitive measure. Only the 3011 participants who scored at or above the mean score of 20 on the total cognitive measure for Wave 1 were included. Of these 3011 participants, $536(17.8 \%)$ reported at Wave 1 that their memory was fair or poor. These 536 did have greater cognitive decline between Wave 1 and Wave 2 (mean $=-1.8$; $\mathrm{SD}=4.2$ ) than the remaining 2475 patients (mean $=-1.1$; $\mathrm{SD}=4.1$ ), who reported having good or better memory 
(t-equal variance $=3.8, d f=3009, P<.001)$. The participants who were above average on the total cognitive score at Wave 1 yet reported poor memory did have lower scores on the Wave 1 total cognitive measures ("fair/poor" memory group, mean $=23.2 ; \mathrm{SD}=2.8$; "good" or "better" group, mean $=24.1 ; S D=3.1 ;$ t-unequal variance $=5.9 ; d f=857$; $P<.001)$. Therefore, a multiple regression was conducted where change in cognitive score between Wave 1 and Wave 2 was the outcome variable and two measures, self-assessment of memory and actual score on the cognitive measure at Wave 1 , were the explanatory variables. Self-assessment of memory ( $\mathrm{t}=-6.7, d f=1, P<.001)$ was a significant predictor of cognitive decline even after controlling for actual cognitive performance at Wave $1(\mathrm{t}=-21.2, d f=1, P<.001)$.

\section{DISCUSSION}

In general, people's assessment of their memory corresponded to their actual performance on cognitive measures in this large community sample of adults aged $\geq 70$. However, large portions of this sample inaccurately assessed their memory decline. People who are functioning well on ADLs and who do not suffer depressive symptoms minimize actual memory decline. In contrast, people whose memory remains stable or improved but suffer disability and depressive symptoms report memory decline inaccurately. These findings offer a unique perspective because depression and functional impairment predicted memory complaint for people at both high and low levels of cognitive functioning.

This study differs from many earlier studies of memory because it used a large community sample, rather than a clinical sample. Differences in sample composition may account for the discrepant findings from prior studies about memory complaint. People in this community sample seem to be able to assess their own memory abilities. The mean on all cognitive measures always fell between people reporting "good" memory and people reporting "fair" memory. This finding suggests that people are aware of how their memory compares with others and that they are able to make the connection between their everyday difficulties with memory and the concept of memory represented in cognitive tests. The conditions that tended to skew people's self-assessment such as depression and impaired independent functioning are the ones that led them to seek treatment. Therefore, clinicians are more likely to come into contact with older people who are poor judges of their own memory which may give the general impression that most older people cannot assess their own cognitive skills.

Depressive symptoms were associated with a greater likelihood of reporting memory impairment. The stronger association between the revised CES-D measure of depressive symptoms and memory impairment as compared with the short-form CIDI may result from the fact that this scale measures depression for the week before the interview and is, therefore, more current than the short-form CIDI, which assesses depression occurring at any time during the year before the interview. However, it may also reflect the superiority of a continuous measure in capturing clinically significant depressive affect in an older population.

The importance of affective status and independent living skills are probably interrelated. People with loss of functioning are likely to experience demoralization that would spread to their assessment of other areas of functioning. People may not be able to make the distinction between different domains of functioning when they asked to rate their memory. It is also possible that the direct effects of depression on memory performance contributed to the findings in this study.

People who reported impairment at Wave 1 but scored above average on the cognitive test did show greater cognitive decline by Wave 2 when compared with the people who reported that their memory was intact. This finding remained significant even after controlling for differences in scores on the baseline cognitive measure. This suggests that the subjects were sensitive to cognitive impairment that was not reflected by the cognitive measures at Wave 1 .

This study had some methodological limitations that must be considered when interpreting these results. In AHEAD, institutionalized individuals were not recruited in Wave 1 of the study, although they remained in the sample if they were institutionalized between Wave 1 and Wave 2 . In addition, it is possible that proxy interviews were more common for those who were already experiencing early dementia and did not participate in the full interview. Therefore, a group of individuals with dementia may have been systematically screened out of the sample, making it less representative of the full range of cognitive functioning seen in older people.

Although the measures of memory contain items represented in most standard cognitive measures, the cognitive measures in this study are limited in scope and are not a substitute for a full cognitive assessment administered in a clinic setting. Nor did we determine dementia status. Similarly, the questions regarding self-assessment were minimal when compared with some of the more detailed scales currently in use. As with any large community study, the quality of assessment was limited by the logistic demands of assessing 5000 individuals sampled from the entire United States.

This study suggests that people's self-assessment of memory is influenced by their functioning in a wide range of domains. Clinicians should be aware that self-assessment of memory is influenced by many conditions that bring people to treatment such as impairment. When a cognitively impaired person denies memory loss, intervention by a clinician can be extremely beneficial in terms of implementing appropriate safety measures and offering support. It may be difficult for some to understand that although they are physically capable of cooking, driving, or traveling, doing these tasks poses a potential risk that may often necessitate involvement of family or caregivers in maintaining their safety. Conversely, people with poor health or limited independent functioning should be heartened to learn that this does not necessarily mean that their "mind is going." Older persons at both the high and low end of cognitive functioning would benefit from such education so that they can engage in tasks appropriate for their level of functioning.

\section{REFERENCES}

1. Rabinowitz JC, Ackerman BP, Craik FI, Hinchley JL. Aging and metamemory: The roles of relatedness and imagery. J Gerontol 1982;37:688-695.

2. Jonker C, Launer LJ, Hooijer C, Lindeboom J. Memory complaints and memory impairment in older individuals. J Am Geriatr Soc 1996;44:44-49.

3. Christensen $H$. The validity of memory complaints by elderly persons. Int J Geriatr Psychiatry 1991;6:307-312.

4. Larrabee GJ, Levin HS. Memory self-ratings and objective test performance in a normal elderly sample. J Clin Exp Neuropsychol 1986;3:275-284.

5. Gagnon M, Dartigues JF, Mazaux JM et al. Self-reported memory complaints and memory performance in elderly French community residents: 
Results of the PAQUID research program. Neuroepidemiology 1994;13:145-154.

6. Kahn RL, Zarit SH, Hilbert NM, Niederehe G. Memory complaint and impairment in the aged: The effect of depression and altered brain function. Arch Gen Psychiatry 1975;32:1569-1573.

7. O'Connor DW, Pollitt PA, Roth $\mathrm{M}$ et al. Memory complaints and impairment in normal, depressed and demented elderly persons identified in a community survey. Arch Gen Psychiatry 1990;47:224-227.

8. Sunderland A, Watts K, Baddeley AD, Harris JE. Subjective memory assessment and test performance in elderly adults. J Gerontol 1986;41:376-384.

9. Bolla KI, Lindgren KN, Bonaccorsy C, Bleeker ML. Memory complaint in older adults: Fact or fiction? Arch Neurol 1991;48:61-64.

10. McGlone J, Gupta S, Humphrey D et al. Screening for early dementia using memory complaints from patients and relatives. Arch Neurol 1990;47:1189-1193.

11. Fisher CM. Neurological fragments. II. Remarks on anosognosia, confabulation, memory and other topics; and an appendix on self-observation. Neurology 1989;39:127-132.

12. Rabbitt P, Abson V. "Lost and found." Some logical and methodological limitations of self-report questionnaires as tools to study cognitive ageing. Br J Psychol 1990;81:1-16.

13. Hultsch DF, Hertzog C, Dixon RA. Age differences in metamemory: Resolving the inconsistencies. Can J Psychol 1987;41:193-208.

14. Schmand B, Jonker C, Hooijer C, Lindeboom J. Subjective memory complaints may announce dementia. Neurology 1996;46:121-125.

15. Flicker C, Ferris SH, Reisberg B. A longitudinal study of cognitive function in elderly persons with subjective memory complaints. J Am Geriatr Soc 1993;41:1029-1032.

16. O'Hara MW, Hinrichs JV, Kohout FJ et al. Memory complaint and memory performance in the depressed elderly. Psychol Aging 1986;1:208-214.

17. Plotkin DA, Mintz H, Jarvik LF. Subjective memory complaints in geriatric depression. Am J Psychiatry 1985;142:1103-1105.

18. West RL, Boatwright LK, Schleser R. The link between memory performance, self-assessment and affective status. Exp Aging Res 1984;10:197200.

19. Scogin F. Memory complaints and memory performance: The relationship re-examined. J Appl Gerontol 1985;4:79-89.
20. Soldo BJ, Hurd MD, Rodgers WL, Wallace RB. Asset and health dynamics among the oldest old: An overview of the AHEAD study. J Gerontol 1997; 52B:1-19.

21. Burkhauser RV, Gertler PJ. The Health and Retirement Study: Data quality and early results. Journal of Human Resources 1995;30:s1-86.

22. Herzog AR, Wallace RB. Measures of cognitive functioning in the AHEAD study. J Gerontol 1997;52B:37-48.

23. Brandt J, Spencer $M$, Folstein $M$. The telephone interview for cognitive status. Neuropsychiatry Neuropsychol Behav Neurol 1988;1:111-117.

24. Folstein MF, Folstein SE, McHugh PR. "Mini-mental state." A practical method for grading the cognitive state of patients for the clinician. J Psychiatr Res 1975;12:189-198.

25. Worid Health Organization. Composite International Diagnostic Interview (CIDI, Version 1.0). Geneva: World Health Organization, 1990.

26. Kessler RC, McGonagle KA, Sanyang $\mathrm{Z}$ et al. Lifetime and 12-month prevalence of DSM-III-R psychiatric disorders in the United States. Results from the National Comorbidity Study. Arch Gen Psychiatry 1994;51:8-19.

27. American Psychiatric Association. DSM-IV: Diagnostic and Statistical Manual of Mental Disorders, $4^{\text {th }}$ Ed. Washington, DC: American Psychiatric Press, 1994.

28. Radloff LS, Teri L. Use of the Center for Epidemiologic Studies-Depression Scale with older adults. Clinical Gerontologist 1986;5:119-135.

29. Turvey $\mathrm{CL}$, Wallace $\mathrm{RB}, \mathrm{Herzog} \mathrm{R}$. The relation between a revised CES-D measure of depressive symptoms and a DSM-based measure of major depressive episodes in the elderly. Int Psychogeriatr 1999;11:139-148.

30. Rodgers W, Miller B. A comparative analysis of ADL questions in surveys of older people. J Gerontol 1997;52B:21-36.

31. Katz S, Ford AB, Moskowitz RW et al. Studies of illness in the aged. The index of ADL: A standardized measure of biological and psychosocial function. JAMA 1963;185:914-919.

32. Kane RA, Kane RL. Assessing the Elderly. Lexington, MA: Lexington Books, 1981.

33. Weiner JM, Hanley RJ, Clark R, VanNostrand JF. Measuring the activities of daily living: Comparisons across national surveys. J Gerontol 1990;45: S229-\$237.

34. Fillenbaum GG. Screening the elderly: A brief instrumental activity of daily living measure. J Am Geriatr Soc 1985;33:698-706.

35. Lawton MP, Brody E. Assessment of older people: Self-maintaining and instrumental activities of daily living. Gerontologist 1969;9:179-186. 